\title{
ANCAMAN POLA PERILAKU FINANSIAL TEKNOLOGI TERHADAP EKSISTENSI INDUSTRI PERBANKAN DI INDONESIA
}

\author{
Mumammad Richo Rianto ${ }^{1}$, Eri Bukhari ${ }^{2}$, Adi Wibowo Noor Fikri ${ }^{3}$ \\ Program Studi Manajemen, Fakultas Ekonomi, Universitas Bhayangkara Jakarta Raya, Jl. Raya Perjuangan \\ No.1, Bekasi \\ richorianto@gmail.com ${ }^{1}, \underline{\text { eri_bukhari@yahoo.com }}{ }^{2}, \underline{\text { noor.fikri@gmail.com }}^{3}$
}

\begin{abstract}
Abstrak
Tujuan dari penulisan ini adalah untuk mengantisipasi ancaman finansial teknologi terhadap eksistensi industri perbankan di ndonesia, karena dewasa ini kemajuan technologi sudah tidak dapat dihindari lagi, hal ini dibuktikan dengan fenomena yang terjadi saat ini dimana Indonesia menjadi negara dengan salah satu masyarakat dengan pengguna internet terbesar di dunia. Metodologi yang dignakan adalah deskriptif kualitattif dengan menggambarkan atau melukiskan fakta-fakta, atau gejala yang terjadi saat ini terhadap pesatnya perkembangan financial teknologi dalam menyonsong era digitalisasi revolusi industry 4.0, khususnya dalam indutri perbankan. Hasilnya adalah perubahan manajemen merupakan suatu keharusan yang tidak bisa dielakkan bagi Industri ini agar tetap bertahan dalam persaingan . melalui pendekatannya memberikan petujuk dalam melakukan perubahan dengan menggunakan 3 pertanyaan : (1) "mengapa harus berubah ?”, (2)“ Apa yang harus berubah ?”, (3) “ Bagaimana melakukan perubahan ?”. Pertanyaan ini akan menjawab alternatif terbaik dalam melakukan proses perubahan tersebut., sehingga dapat dikembangkan strategi yang harus dilakukan oleh Industri perbankan dalam menghadapi perubahan.
\end{abstract}

Kata Kunci : Finansial, Teknologi, Indutri Perbankan

\begin{abstract}
:
The purpose of this paper is to anticipate the financial threat of technology to the existence of the banking industry in Indonesia, because today technological advances are unavoidable, this is evidenced by the phenomenon that occurs today where Indonesia is a country with one community with internet users biggest in the world. The methodology used is descriptive qualitative by describing or describing the facts, or symptoms that occur today towards the rapid development of financial technology in addressing the digitalization era of the industrial revolution 4.0, especially in the banking industry. The result is a change in management is a necessity that cannot be avoided for this industry in order to survive in competition. through its approach provides guidance in making changes using 3 questions: (1) "why should it change?", (2) "What must change?", (3) "How to make changes?". This question will answer the best alternative in carrying out the change process, so that strategies can be developed by the banking industry in the face of change.
\end{abstract}

Keywords : Financial, Technology, Banking Industry

\section{PENDAHULUAN}

Perekembangan Industri keuangan beberapa dekcade ini menunjukan pertumbuhan yang sangat significant. Para investor kini menjadikan bank tidak hanya sebagai tempat penyimpanan uang meliankan sebagai one stop shopping dalam transkasi keuangan. Perbankan kini menjadi alat investasi, asuransi dan lifestyle.
Namun dalam perkembangannya industryi perbankan tidak didukung oleh kemampuan manager dan stakeholder dalam membaca perubahan lingkungan yang dynamis, karena. Lingkungan yang dynamis dan fluktuatif kini mulai menjadi ancaman bagi industry perbankan khususnya masuknya era digitalisasi revolusi industry 4.0. Perubahan ini dimulai ketika 
munculnya fenomena disruption, bigdata dan IOT (internet of things).

Menurut Kementrian Komunikasi dan Informatika, pada tahun 2018 pertumbuhan pengguna internet mengalami kenaikan sangat signifikan, dimana pada 2016 mencapai 132,7 juta jiwadari total penduduk 256,2 Juta jiwa dan pada 2017 tumbuh menjadi 143,26 Juta jiwa. Hal ini menjadikan Negara Indonesia sebagai 28okum28 bagi investor local dan International untuk tumbuh dan mengembangkan Teknologi Informasinya, khususnya Finansial Teknologi.. Sedangkan menurut Bank Indonesia tahun 2016 mendefinisikan Financial Technologi merupakan hasil gabungan antara jasa keuangan dan tehnologi yang akhirnya mengubah model bisnis dari konvensional menjadi moderat, yang awalnya dalam membayar harus bertatap muka dan membawa sejumlah uang kasm kini dapat melakukan transkasi jarak jauh dengan melakukan pembayran yang dapat dilaukan dalam hitungan detik saja.

Dengan beralihnya perilaku masyarakat yang kini lebih memilih mode transaksi baru yang mudah, aman, dan fleksibel seperti Alipay (Dana), Go-Pay , Ovo, Doku dan lain sebagainya, membuat industri ini harus merubah management (Change Management) yang dulu masih bersifat konvensional menjadi financial technologi yang lebih baik dan dapat bersaing dengan sehat di era digital dan era globalisasi saat ini. Apabila hal ini dibiarkan akan berdampak pada profitabilitas industri perbankan dan secara umum akan mengancam pertumubuhan ekonomi diIndonesia.

\section{TINJAUAN PUSTAKA}

Bank Indonesia (Indonesia, 2016) dalam mengantisipasi dan mengatur jalannya lalulintas Financial Technology, kemudian mengeluarkan peraturan 28okum yang menjelaskan tentang transkasi Financial Technology (1) Peraturan Bank Indonesia No. 18/40/PBI/2016 tentang penyelenggaraan pemrosesan Transaksi Pembayaran (2) Surat Edaran Bank Indonesia No 18/22/DKSP perihal Penyelenggaraan Layanan Keuangan Digital (3) Peraturan Bank Indonesia No 18/17/PBI/2016 Tentang Uang Elektronik. Bank Indonesia juga mengeluarkan listing Financial technology tahun 2018 sebanyak 30 pelaku Finansial Teknologi dengan berbasis server yang sudah memiliki izin untuk melakukan usaha di Indonesia. Melihat pesatnya pertumbuhan financial technology di Indonesia membuat banyak Industri yang kini mulai merasakan ancaman yang sangat tinggi dari munculnya mode perilakubarudalambertransaksidenganmenggunakan technologyatauyanglebihdikenaldengan Financal Technology (Fintech), salah satu nya adalah IndustriPerbankan. Sedangkan Indonesian Banking Statistik (Keuangan, 2018) mempublikasi bahwa ada sebanyak 115 Bank Umum dengan jumlah kantor cabang sebanyak 31.555 buah dan 1.597 Bank Perkreditan Rakyat (BPR) yang dengan jumlah kantor cabang sebanyak 6.260 di seluruh Indonesia.

\section{METODOLOGI PENELITIAN}

Dalam penulisan ini penulis menggunakan metodologi deskriptif kualitattif dengan menggambarkan atau melukiskan fakta-fakta, atau gejala yang terjadi saat ini terhadap pesatnya perkembangan financial teknologi dalam Menyonsong era digitalisasi revolusi industry 4.0, khususnya dalam indutri perbankan.

\section{HASIL DAN PEMBAHASAN}

Perubahan adalah suatu keniscayaan, karena menurut (ROSABETH MOSS KANTER, 1999) perubahan organisasi saat ini menjadi cara hidup bagi sebagian besar perusahaan. Namun untuk merubah sebuah organisasi atau perusahaan tidaklah mudah.Dalam artikel yang ditulis oleh Jan Erland Jansson menjelaskan bahwa ada 3 pertanyaan penting dalam sebuah organisasi dalam menghadapi management perubahan (Change Management). Investigasi ini dibutuhkan untuk dapat menganaisa tingkat perubahan yang nanti akan memberikan alternative alternative pilihan serta rekomendasi yang memungkinkan untuk dapat diambil. (Jansson, 2009) menjelaskandalam investigasi perusahaan harus dapat menjawab 3 pertanyaan penting, yaitu Why? What? dan How?

\section{Pertanyaan "MENGAPA" harus berubah?}

Pertanyaan ini menyoroti kepada hubungan sebab dan motivasi "mengapa"? sebuah perusahaan harus berubah. Pertanyaan ini adalah sebagai dasar motivasi yang nntinya akan menghubungkan dengan tujuan yang ingin dicapai oleh perushaan serta visi dan misi yang ingin di capai. Perbankan di Indoensia sebagian besar masih menggunakan cara tradisional (konvensional) dalam pengoperasiannya. Hal ini akan berakibat fatal 
untuk perkembangan industri perbankan di era 4.0 dimana saat ini sudah masuk ratusan aplikasi finansial teknologi ke Indonesia dan ribuan aplikasi telah tersebar di seluruh dunia. Industri Perbankan saat ini masih menilai bahwa teknology adalah sebuah "layanan tambahan bagi Pelanggan" sebut saja mobile banking dan Internet Banking, padahal pada era digital 4.0 ini perubahan itu sudah masuk kedalam jiwa dan ruh Industri perbankan itu sendiri yaitu Change Management dalam Industri itu sendiri.

Change Management dalam Industri perbankan harus muncul karena persaingan dengan mode peer to peer sudah mulai bermunculan. Saat ini para Debitur cukup mendownload sebuah aplikasi untuk melakukan pinjaman pada sebuah aplikasi dengan proses kurang dariljam, namun hal ini tidak dilakukan oleh perbankan konvensional karena system birokrasi yang masih konvensional dan pertauran dari Bank Indonesia yang belum mempuni, padahal sumber pendapatan terbesar dari industri perbankan ini adalah dari Debitur. Hal ini juga terjadi pada kreditur, perubahan pola perilaku masyrakat saat ini menunjukkan bawah masyarakat lebih senang untuk membelanjakan uangnya melalui aplikasi Go-pay, OVO atau Dana (Alipay) yang dinilai lebih fleksibel, terintegasi dan mendapatkan potonganharga.

(ROSABETH MOSS KANTER, 1999) menunjukkan tiga kekuatan yang harus dilmiliki sebuah perusahaan dalam proses transformasi change management adalah Globalisasi, Teknologi Informasi dan Konsolidasi antar Industri. Hal inilah yang kini mulai dilakukan oleh Financial teknologi (Fintech) misalnya Gopay, Ovo, Dana (Alipay). Bagi perusahaan fintech mengembangkan IT memungkinkan untuk megadopsi tiga kekuatan yang ditemukan dalam Kanten (1999). Alipay adalah salah satu aplikasi terbesar di dunia yang sudah menjalankan konsep tersebut, dimana kemajuan tehnologi ini membuat turis manca Negara dapat menggunakan pembayaran ini 29okum29 diseluruh dunia, tak terkecuali Indonesia ( Bali). Alipay membut sinkronisasi pembayaran menggunakan aplikasi yang dapat memberikan banyak keuntunganbagi customer diantaranya lebih murah, transkasi fleksibel, cashless, terkoneksi dengan hotel dan shopping center serta potongan harga. Perlunya menemukan pendekatan baru dalam perbankan merupakan tantanan terbesar saat ini sebelum market share bank menjadi hilang karena terlindas oleh perubahan tak terkecuali Industri Perbamkan.

\section{Pertanyaan "APA" yang harus berubah?}

Pertanyaan ini membantu untuk mengidentifikasi area bisnis mana yang perlu mendapat perubahan dan pengembangan. Untuk menjawabnya kita harus merumuskan dulu beberapa hal seperti apa yang ingin di capai oleh perusahaan? Apakah cara yang digunakan sudah tepat? Untuk mengidentifikasi apa yang diubah, analisa straegi harus mempertimbangkan pertangaan apa adalah sebagai berikut 1).Apa yang harus dilakukan untuk dapat mengidentifikasi ancaman lingkungan eksternal perbankan ? (2). Apa yang dbutuhkan agar seluruh system dapat berjalan dengan baik ? (3). Apa yang dibutuhkan untuk memenuhi target yang di inginkan oleh pemegang saham dengan merubah management yang lebih effisien. (4). Strategi apa yang dapat menjadikan bank dapat berkompetisi dengan finansial technologi? (5).Apa yang menjadi ukuran sistem telah berubah dan dapat bersaing ? (6) apa prioritas yang harus dirubah, dan seterusnya. Pertanyaan ini dibuat agar manajemen perbankan memiliki arahan dan indikator dalam melakukan perubahan sesuai dengan culture dan tujuan perusahaan.

a. Pertanyaan "BAGAIMANA" melakukan perubahan?

Setelah melakukan investigasi pada pertanyaan "mengapa" dan "apa"? kemudian identifikasi yang terakhir adalah menjawab pertanyaan "Bagaimana"? Pertanyaan ini dapat dibagi menjadi dua bagian. Bagian pertama adalah bagaimana merubah system yang sudah berlandaskan 29 okum dan merupakan SOP yang merupakan kebijakan dari otoritas jasa keuangan (OJK) dan Bank Indonesia mengenai peraturan dan pengoperasian perbankan.Hal ini akan terasa sulit jika tidak adanya campur tangan dari pihak pemerintah yang berkepentingan. Pemerintah harus menjadi pelindung dan pengatur terbaik bagi Industri yang ada di dalam wilayahnya, khususnya Industry perbankan.

Bagian kedua adalah bagaimana cara untuk merubah manajemen internal dalam perusahaan, dimana akan banyak orang orang yang merasakan dampak dariperubahan tersebut. Pertanyaan bagi mana ini dapat disusun sebagai berikut: (1) Bagaimana menyeimbangkan antara berbagai sumber daya dalam perusahaan? (2) Bagaimana merubah system yang sudah ada agar dapat mengadopsi model prilaku transkasi saat ini? (3) Bagaimana perubahaan dapat menimbulkan kesejahteraan bagi para pegawai dan bagi pemegang saham? dan lain sebagainya. 
Pertanyaan ini akan memberikan banyak pilihan dan alternative bagi para pengambil keputusan, dimana setiap orang yang terlibat dalam proses perubahan dengan divisi yang berbeda dan tanggung jawab yang berbeda dalam menyelesaikan masalah nya. Perusahaan harus melakukan perubahan dengan sangat hati hati agar perubahan tersebut tepat sasaran dan tidakmengakibatkan gejolak pada system management dan operasional perusahaan. Dalam penelitian (Jansson, 2009) dikutip dari Nickols (2004) membuat sebuah rumusan dalam melakukan rencana perubahan, sehingga akan berdampak baik bagi perusahaan.

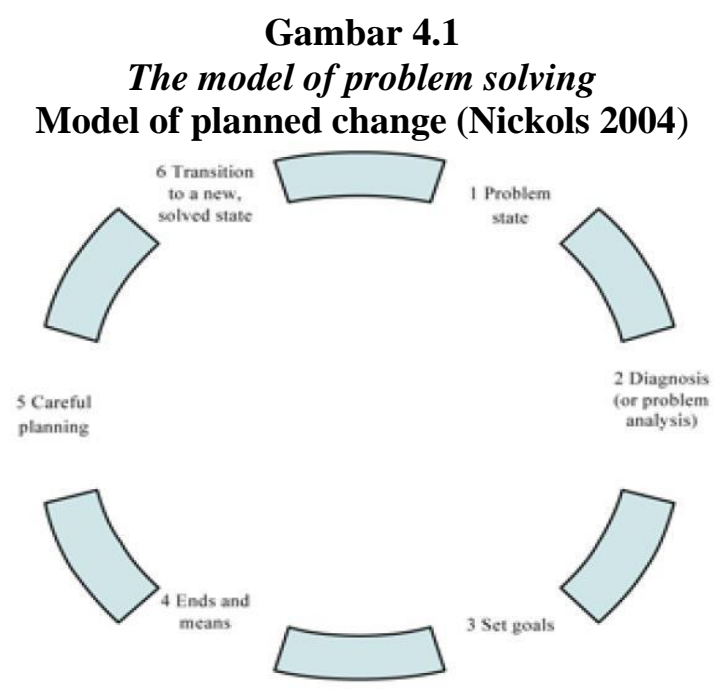

Model kerangka kerja ini menunjukkan bagaimana proses perubahan yang terencana dengan hati hati bagi kemajuan sebuah perusahaan. Titik awal dari sebuah perubahan adalah "Masalah". Banyak orang menganggap bahwa masalah adalah sebuah makna negative, namun kata "masalah" dapat diartikan juga sebagai "peluang", yaitu situasi mendasar yang mengharuskan perusahaan berubah kearah yang lebih baik. Bahkan kesediaan untuk berubah harus dilakukan tanpa adanya masalah yang kemudian mulaimuncul. Pada dasarnya model ini hanya sebagai gambaran terencana dari sebuah Change Management dan sangat mungkin para manager akan mengahadapi situasi keadaan yang tidak terduga dan ini memerlukan pendekatan serta fleksibelitas dalam menjalankannya.

Dalam model ini bagian pertama adalah menemukan permasalahan yang merupakan ancaman yang menjadi focus dari munculnya masalah sehingga berpengaruh terhadap existensi keberlangsungan perusahaan. Tahap kedua dilanjutkan dengan menganalisis masalah serta mendiagnosa munculnya masalah sehingga dapat berdampak megancam perusahaan baik secara internal maupun eksternal. Pada tahap ketiga adalah menentukan tujuan dari penyelesaian ancaman yang telah di diagnose dan di analysis. Pada tahap berikutnya pemecahan masalah menggunakan MEA (Means-Ends Analaysis), yaitu pemecahan masalah berdasarkan pembagian masalah masalah kedalam kelompok kelompok tertentu. MEA juga dapat disimpulkan sebagai strategi dalam pemecahan masalah yang membuatnya lebih sederhana dengan memberikan alternative alternative dan petunjuk dalam penyelsaian masalah secara efektif dan efisien. Tahap ke lima berikutnya membuat planning atau rencana dalam pemecahan masalah secara terstruktur dan detail, sehingga dapat di impelementasikan dengan baik dan tahap yang terakhir adalah melakukan perubahan yang telah disusun dalam perencanaan yang telah dibuat. Tahapan ini masuk kedalam proses transisi untuk penyelesaian masalah. Dalam transisi ini alternatif yang dibuat dapat berjalan dengan baik atau sebaliknya, jika terjadi miss maka akan menjadi problem baru yan akan kembali lagi menjadi problem yang harus diselasaikan.

b. Reaksi karyawan dan bagaimana mencapai kesepakatan dalam perubahan

Dalamprosesperubahanmanagerharusmemp ertimbangkanreaksiorangorangterhadap

perubahan dan kecepatan dalam pengimplementasiannya. Selain itu manager harus dapat mengadopi konsep hubungan perubahan dan transformasi? Kesalahan terbesar dalam proses perubahan adalah tanpa terlebih dahulu mengalokasikan sumber daya yang diperlukan - waktu, pengetahuan dan financial yang mapan. Seorang Manager harus dapat meyakinkan karyawan pentingnya sebuah perubahan. Menurut (Jansson, 2009) dikutip dari (Worley \& Vick 2005) memberikan pernyataan bahwa perubahan yang dilakukan dengan buruk seringkali lebih buruk dibandingkan perubahan yang tidak pernah dilakukan sama sekali. Karena perubahan yang buruk akan mengakibatkan mainset negative dan mengakibatkan perubahan akan semakin sulit dimasa yang akandatang.

Industry perbankan saat ini banyak diisi oleh orang orangyang melalui program ODP (Officer Development Program), dimana program ini dikhususkan bagi mereka dengan kualitas kompentensi dan capability yang lebih 
baik serta rata rata umur yang masih tergolong millennial. Dengan pemahaman dan sumberdaya yang lebih baik memungkinkan industry perbankan akan lebih mudah dalam mengontrol sumberdaya yang ada didalamnya. Namun mungkin pasti ada keterbatasan keterbatasan yang akan ditemui manager dalam proses perubahan.

c. Membangun Komunikasi

Sumberdaya yang paling penting dalam proses perubahan adalah manusia. Komunikasi antara Direktur Utama dan bawahnnya pada industry bank sangat penting, baik di level kepaladivisi, kepala cabang, supervisor, hingga ke pelaksana dan pegawai dasar. Perubahan ini harus terinformasikan kesebanyak sumberdaya yang ada di dalam perusahaan karena akan berdampak kesemua orang yang terlibat di dalamnya.Indonesia dengan culture ketimuran membuat komunikasi ini dapat terjalin dengan lebih mudah dan hangat, namun kendala yang dihadapi dalam proses komunikasi adalah tingkat pengetahuan dan pendidikan yang berbeda membuat presepsi akan perubahan itu sendiri dimaknai berbeda. Dalam membangun informasi yang tepat sasaran dapat dibangun cluster atau groupdiscussion sesuai dengan level dan tingkat pendidikan. Komunikasi yang baik dan terstruktur akan memberikan efek yang baik bagi perubahan dalam organisasi dan sebaliknya komunikasi yang kurang baik akan menghambat proses perubahan dalam perusahaan atau organisasi.

\section{KESIMPULAN}

\section{Kesimpulan}

Dalam perkembanganya indutri perbankan harus dapat mengantisipasi perubahan lingkungan yang dynamis terutama iklim yang dipengaruhi oleh pola prilaku baru yang terbentuk dari kemajuan tehnologi. Pada bagian ini peneliti ingin memberikan kesimpulan sebagai berikut:

1. Kementrian KOMINFO mempublikasi jumlah pengguna internet yang semakin meingkat dari tahun 2016 hingga 2017 dan2018 artinya jumlah pengguna internet di Indonesia mempeliki potensi yang sangat besar dan bertumbuh scara significant dari tahun ke tahun.

2. Perubahan lifestyle transkasi masyarakat Indonesia mulai berubah dengan masuknya Finansial Teknologi. Pola perilaku baru yang merubah kebiasaan masyarakat yang bertransaksi menggunakan perbankan mulai beralih menggunakan Finansial Tehnologi.

3. Pemerintah melalui Bank Indonesia telah membuat berbagai peraturan untuk mengawasi pelaku dan transaksi dengan menggunakan mediadigital.

4. Finansial teknologi bermunculan ratusan bahkan ribuan di seluruh dunia dan kini sudah masuk keIndonesia.

5. Perbankan adalah salah satu industri yang mendapat ancaman dari masuknya finansial teknologi keIndonesia.

6. Jumlah perbankan yang banyak akan berdampak buruk bagi perekonomian jika tidak melakukan perubahan.

7. Kanter(1999)menjelaskanmengenaiprosesperu bahandenganmelakukaninvestigasidari pertanyaan "APA",danBagaimana?

"Mengapa",

8. Pertanyaan ini akan memberikan alternative alternative jawaban dan rekomendasi yang dapat diambil dalam proses perubahan.

9. Perubahan mengakibatkan reaksi dari lingkungan internal dan eksternal

10. Membangun komunikasi yang baik merupakan kunci dari proses perubahan yangmatang.

\section{Saran}

Berdasarkan kesimpulan diatas penulis merekonmendasikan sebabagai berikut

1. Mengidentifikasi pertumbuhan pengguna internet yang nanti akan beralih ke Financial tehnology sebagai perilaku baru dalam transaksikeuangan.

2. Mengidentifikasipolapolafinancialtechnologyd alammenjelankanbisnisnyabaikmarket share, strategy dan implementasi serta technology ygdigunakan.

3. Pemerintahsebagaipelindungdanpengaturlaluli ntasharusdapatmembuatpayunghukum yang dapat mengakomodir setiap kegiatan financial mis: izin, standar bunga, standar mitigasi resiko, dan persyaratan yang harus dipatuhi oleh setiappelaku.

4. Membangun system informasi yang sesuai dengan kebutuhan hingga 10 hingga 30 tahun yang akandatang

5. Membangunstrategydanganmengidentifikasida nmengadopidariFintechyangsudahada agar dapat bersaing dan survive serta sustainability dalam menjalankanbisnis

6. Membangun strategy yang tepat dalam proses perubahan dengan terencana dan penuh kehatihatian 
7. Membangun kerjasama dan komunikasi ke semua Industry yang nntinya akan menjadi partner bagi Industryperbankan.

8. Perlunya memberikan informasi yang tepat kepada seluruh sumberdaya yang ada dalam organisasi mengenai perubahan yang akandilaukan.

9. Pengalokasian dalam proses Transformasi memerlukan waktu, pengetahuan dan financial yang cukup dan merupakan sesuatu yang harus dipersiapkan denganmatang.

10. Perlunya pengukuran perubahan pada proses perubahan, sehingga organisasi tidak mengalami delusi dalam perubahan tersebut.

\section{DAFTAR PUSTAKA}

\section{Indonesia, B. (2016). FINANCIAL TECHNOLOGY edukasi perlindungan konsumen. Retrieved from https://www.bi.go.id/id/edukasi- perlindungan-konsumen/edukasi/produk- dan-jasa- sp/fintech/Pages/default.aspx \\ Jansson, J. (2009). The importance of change management in reforming Customs. World Customs Journal, 2(2), 41-52. Retrieved from http://worldcustomsjournal.org/media/wcj/- 2009/1/WCJ_Volume_3_Number_1.pdf\#pag $\mathrm{e}=41$}

Kementrian Komunikasi dan Informatika. (2018). SIARAN PERS NO.

53/HM/KOMINFO/02/2018. SIARAN PERS NO. 53/HM/KOMINFO/02/2018, 1 . Retrieved

from

https://kominfo.go.id/index.php/content/detai 1/12640/siaran-pers-no-

53hmkominfo022018-tentang-jumlahpengguna-internet-2017-meningkat-kominfoterus- lakukan-percepatan-pembangunanbroadband/0/siaran_pers

Keuangan, O. J. (2018). Statistik Perbankan Indonesia, 3. Retrieved from https://www.ojk.go.id/id/kanal/perbankan/dat a-dan-statistik/statistik-perbankanindonesia/Pages/Statistik-PerbankanIndonesia---November-2018.aspx

Nickols, F 2004, Change management 101: a primer, Distance Consulting, Howard, $\mathrm{OH}$, http://home.att.net/ nickols/change.htm.

ROSABETH MOSS KANTER. (1999). The enduring skills of change leaders',.Leader to Leader, (summer), 15-22.
Worley, CG \& Vick, YH 2005, 'Leading and managing change: leading change management involves some simple, but too often forgotten rules', Graziadio Business Report, Pepperdine University, vol.8, no.2. 